\title{
Functionalization of Iron Oxide Magnetic Nanoparticles with the Multivalent Pseudopeptide N61 for Breast Tumor Targeting
}

Maha Sader ${ }^{1,2}$, Pierre Couleaud ${ }^{3,4}$, Gilles Carpentier ${ }^{1,2}$, Maud-Emmanuelle Gilles ${ }^{1,2}$, Noureddine Bousserrhine ${ }^{1,5}$, Alexandre Livet ${ }^{1,5}$, Ilaria Cascone $^{1,2}$, Damien Destouches ${ }^{1,2}$, Aitziber L Cortajarena ${ }^{3,4}$ and José Courty ${ }^{1,2 *}$

${ }^{1}$ University Paris-Est, UPEC, F-94000, Creteil, France

${ }^{2}$ CNRS, ERL 9215, Laboratory for Research on Cell Growth, Tissue Repair and Regeneration (CRRET), F-94000 Créteil, France

3IMDEA Nanoscience, University City in Cantoblanco, 28049 Madrid, Spain

${ }^{4}$ Central National Biotechnology (CNB-CSIC) - IMDEA Nanoscience Associated Unit "Nanobiotechnology Unit" University Campus Cantoblanco, 28049 Madrid, Spain

${ }^{5}$ Institute Ecology and Science of the Paris Environment (ISSE Paris), Soleo Department ("Soil and Water") Team DIIM, 94000 Créteil, France

\begin{abstract}
Functionalized iron oxide magnetic nanoparticles (MNP) are an innovative tool for cancer detection and treatment. In this study, a cell-surface nucleolin antagonist, N6L, was used as targeting ligand for MNP. This N6L, which exhibits antitumor activities, specifically targets bind tumor cells by binding to cell-surface nucleolin and glycosaminoglycans. N6L was covalently conjugated to dimercaptosuccinic acid coated magnetic nanoparticles (MNP-N6L). Using immunoprecipitation, gene invalidation and enzymatic degradation of glycosaminoglycans, we showed that MNP-N6L targets human breast cancer MDA-MB 231 cells through interaction with nucleolin and sulfated glycosaminoglycans. In vivo biodistribution studies were carried out in MDA-MB 231 tumor-bearing mice, using iron detection assay by spectrometric analysis and Prussian blue staining. Whereas both non-functionalized and functionalized nanoparticles were found in liver and spleen, only MNP-N6L was found in the tumor. Our findings indicate that MNP-N6L is a promising targeting system for theranostic applications in cancer detection and treatment.
\end{abstract}

Keywords: Iron oxide magnetic nanoparticles; Tumor targeting; Breast cancer; Nanomedicine; Theranostic

\section{Introduction}

Breast cancer is the most common malignancy in women throughout the world, accounting for more than $25 \%$ of all new cancer diagnoses in 2012, and despite significant improvements in treatment, for 522,000 deaths [1]. These facts clearly indicate the need to improve existing breast cancer treatments and to develop new therapeutic strategies. Nanomedicine, the application of nanotechnology to medicine, is a promising approach for specific cancer cell targeting, diagnosis, and treatment [2]. Among the nanotechnology tools investigated for biomedical applications are the intrinsic magnetic properties exhibited by iron oxide nanoparticles (MNP), which may be used for magnetic resonance imaging in diagnosis and for magnetic hyperthermia in cancer thermotherapy $[3,4]$, as well as for controlled drug delivery [5,6]. Several MNP formulations have been developed for use in early detection and treatment of breast cancer [7]. Conjugated with the HER 2 antibody Herceptin ${ }^{\circledR}$ (trastuzumab), MNP specifically bind to breast cancer cells expressing the HER2 receptor [8]. MNP functionalized with cytotoxic molecules such as doxorubicin display higher antitumor activity in vivo after magnetic guidance to the tumor $[9,10]$. Novel multi-functionalization strategies of MNP with cytotoxic drugs and targeting agents, enabling drug release mainly within tumor cells by the development of intracellular medium-triggered linkers seem to be promising strategies for cancer therapy.

As recently reported in several studies, cell-surface nucleolin is an interesting molecule for tumor cell targeting and anticancer therapy [11]. This ribonucleoprotein, mainly expressed in the nucleoli of quiescent cells, is overexpressed at the cell-surface of activated endothelial cells and in various tumor cell lines [12,13]. Nucleolin was first described as a protein involved in ribosome biogenesis and in DNA and RNA metabolism [14]. Recent studies highlight the importance of cell-surface nucleolin as a receptor for several ligands that play critical roles in tumorigenesis and angiogenesis, such as hepatocyte growth factor [15], pleotrophin [16], midkine [17] and P-selectin
[18]. Accordingly, in order to block tumorigenesis and angiogenesis, various ligands targeting cell-surface nucleolin have been used, such as endostatin [19], aptamer AS1411 [20], F3 tumor-homing peptide [21], and the multivalent pseudopeptide N6L [22].

N6L specifically targets cancer cells, exhibiting antitumor activity in various human tumor cell lines derived from mammary, colorectal carcinoma, melanoma, glioblastoma, and lymphoma, as well as antiangiogenic activity in various in vitro and in vivo experiments $[13,23]$. N6L is currently in phase I/IIa clinical trials (NCT01711398).

Recently, MNP formulations loaded with N6L and effective anticancer drugs such as doxorubicin and gemcitabine have been developed [24]. With respect to this opportunity, the present study proposes to use N6L to functionalize dimercaptosuccinic acid (DMSA) coated MNP (MNP-N6L) through controlled covalent linkage and to use these nanostructures as cargo to target and kill breast cancer cells. We have studied the physical and chemical properties and the in vitro stability of these nanoparticles. We have also investigated MNP-N6L tumor-targeting properties in vitro and in vivo, as well as MNP-N6L biodistribution in mice bearing human xenograft tumors. Our data shows that as compared to the nonfunctionalized MNP, the multivalent pseudopeptide N6L can be used to functionalized MNP to succefully enhance the targeting tumour tissue.

*Corresponding author: Dr. José Courty, Laboratory CRRET, EAC CNRS 7149 University Paris-Est, 61 Avenue du Général de Gaulle, 94000 Créteil, France, Tel: +331 4517 1797; Fax: +331 4517 1816; E-mail: courty@u-pec.fr

Received June 08, 2015; Accepted July 02, 2015; Published July 12, 2015

Citation: Sader M, Couleaud P, Carpentier G, Gilles ME, Bousserrhine N, et al (2015) Functionalization of Iron Oxide Magnetic Nanoparticles with the Multivalent Pseudopeptide N6I for Breast Tumor Targeting. J Nanomed Nanotechnol 6: 299. doi:10.4172/2157-7439.1000299

Copyright: ( 2015 Sader M, et al. This is an open-access article distributed under the terms of the Creative Commons Attribution License, which permits unrestricted use, distribution, and reproduction in any medium, provided the original author and source are credited. 


\section{Materials and Methods}

\section{Synthesis and physicochemical characterization of N6L functionalized magnetic nanoparticles (MNP-N6L)}

N6L was synthesized as previously described [25]. DMSA coated iron oxide nanoparticles (MNP) were provided by Liquid Research LTD and obtained as previously described [26]. All reagents were purchased from Aldrich and used without further purification. Ultrapure reagentgrade water (18.2 $\mathrm{M} \Omega$, Wasserlab) was used in all experiments. Brine is a saturated solution of $\mathrm{NaCl}$ in ultrapure water. All UV-Vis and fluorescence spectra were recorded on a Synergy $\mathrm{H} 4$ microplate reader (BioTek, US) using 96-well plates. Hydrodynamic diameter and zeta potential measurements were determined using a Zetasizer Nano-ZS device (Malvern Instruments, UK). Hydrodynamic diameter and zeta potential were measured in dilute sample suspensions in water at $\mathrm{pH}$ 7.4 using a zeta potential cell.

MNP were covalently functionalized as previously described [24] and the general synthetic pathway is described in Figure 1A. To achieve covalent functionalization with a disulfide bond, a cysteinemodified N6L pseudopeptide (N6L-SH) was synthesized to introduce a single free thiol function. The thiol function was then activated by 2,2'-dipyridyldisulfide in order to obtain a reactive pyridyl disulfide derivative. In parallel, MNP were pre-activated with cysteamine to introduce a controlled quantity of free thiol that reacts with the thiolactivated N6L. Purification of the resulting compound has been carried out, by size exclusion chromatography. After overnight reaction, several washes with brine were carried out to eliminate electrostatically immobilized N6L. Covalently bound N6L was quantified by measuring 2-pyridinethione released during the reaction. The stability of the MNP formulations in different media was studied by measuring hydrodynamic size at an iron concentration of $0.1 \mathrm{mg} / \mathrm{mL}$. The experiments were performed under storage conditions in $\mathrm{H}_{2} \mathrm{O}$ at $4^{\circ} \mathrm{C}$ and experimental conditions in complete DMEM at $37^{\circ} \mathrm{C}$.

\section{Cell culture}

The MDA-MB 231 human breast carcinoma cell line was purchased from ATCC (American Type Culture Collection, US). Cells were cultured in DMEM 4.5 g/L glucose (Invitrogen SARL, Cergy Pontoise, France) supplemented with 10\% FBS (Invitrogen, Cergy Pontoise, France) and $10 \mu \mathrm{g} / \mathrm{mL}$ gentamicin (Invitrogen, Cergy Pontoise, France) under standard culture conditions $\left(37^{\circ} \mathrm{C}, 5 \% \mathrm{CO}_{2}\right.$, humidified atmosphere).

\section{Prussian blue cell staining}

MDA-MB 231 cells $\left(1 \times 10^{5}\right.$ cells/well $)$ were seeded onto glass cover slips in 24-well plates in complete DMEM and grown for 24 hours. Media culture was replaced by 5\% FBS DMEM and cells were treated with MNP or MNP-N6L at $37^{\circ} \mathrm{C}$ for the times indicated. Cells were then washed in PBS and fixed in methanol at $-20^{\circ} \mathrm{C}$ for 10 minutes. Slides were washed twice in distilled water, and then incubated for 15 minutes at room temperature in freshly prepared potassium ferrocyanide $4 \%$ / $\mathrm{HCl} 4 \%(\mathrm{v} / \mathrm{v})$. Slides were then washed 3 times in distilled water, counterstained with $1 \%$ neutral red for 5 minutes, washed twice again in distilled water, air-dried, and mounted in Eukitt ${ }^{\mathbb{B}}$ quick-hardening mounting medium (Sigma-Aldrich, Saint-Quentin Fallavier, France). Images were acquired by using a CoolSNAP color CCD camera (Photometrics, Tucson, US) coupled to a Leitz Aristoplan microscope ( $25 \mathrm{x}$ objective, NA 0.6). Images were then analyzed (cell detection and blue staining quantification) using an homemade plugin for the ImageJ software. This quantification is described in the Supplementary data.
A

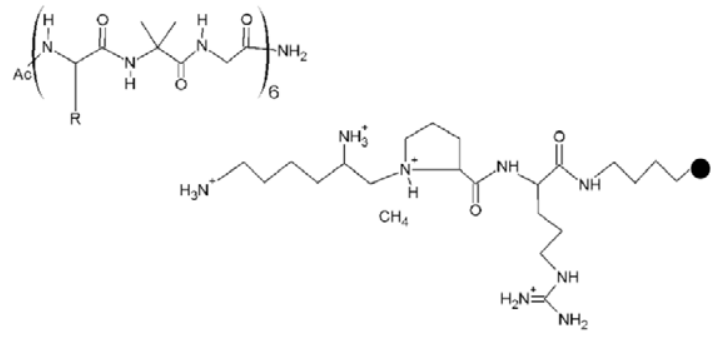

B
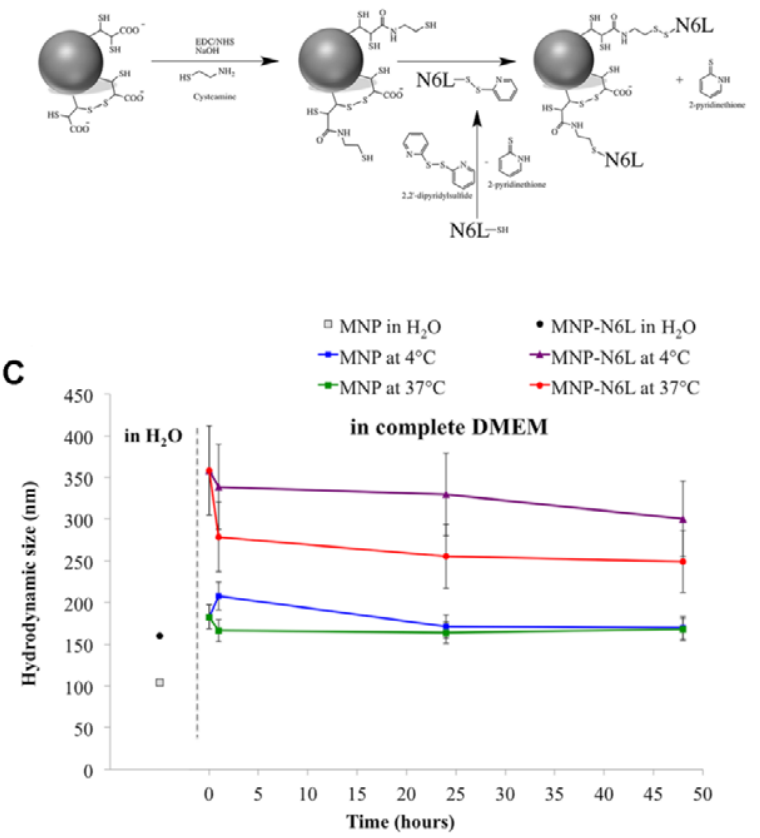

Figure 1: Structure of N6L, general overview of the covalent immobilization strategy of N6L onto MNP, stability characterization and N6L release kinetic. A. Schematic structure of N6L with the K $\Psi P R$ side chains indicated with $R$ (the exact structure of the $K \Psi P R$ subunits is provided on the right side, with the attachment point to the backbone indicated by a black full circle). B. covalent immobilization strategy employed. C. stability studies of MNP and MNP-N6L in complete DMEM (DMEM $+10 \%$ FBS) at $37^{\circ} \mathrm{C}$. Each hydrodynamic size presented is the average of 3 measurements and the error bars represent the average polydispersity index (PDI).

\section{MNP-N6L biodistribution and tumor targeting in vivo}

MDA-MB 231 cells $\left(3 \times 10^{6}\right.$ cells $)$ were subcutaneously injected into the left flank of NMRI nude mice (Janvier). When tumor size reached $200 \mathrm{~mm}^{3}$, mice were randomly separated into three groups: one untreated (control; $n=9$ ) and two intravenously treated with MNP $(n=6)$ or MNP-N6L $(n=9)$ at $10 \mathrm{mg} \mathrm{Fe} / \mathrm{kg}$ body weight (the equivalent of $0.15 \mathrm{mg} / \mathrm{kg}$ of N6L for MNP-N6L) each day for five consecutive days. Two hours after the last injection, mice were sacrificed and tissues were collected and frozen for iron quantification and histological sectioning. Additional informations are given in supplementary methods. All in vivo experiments were carried out under conditions approved by the European Community.

\section{Quantification of iron in tissues}

Tissue samples were digested in DigiPREP MS System (SCP Science, France), successively using AnalaR Normapur nitric acid 
Citation: Sader M, Couleaud P, Carpentier G, Gilles ME, Bousserrhine N, et al. (2015) Functionalization of Iron Oxide Magnetic Nanoparticles with the Multivalent Pseudopeptide N6I for Breast Tumor Targeting. J Nanomed Nanotechnol 6: 299. doi:10.4172/2157-7439.1000299

Page 3 of 8

$\left(69 \% \mathrm{~m} / \mathrm{v}, \mathrm{VWR}\right.$, France) at $80^{\circ} \mathrm{C}$ and hydrogen peroxide $(30 \% \mathrm{v} / \mathrm{v}$, Trace SELECT ${ }^{\circledR}$ Ultra), for ultratrace analysis (Fluka, Germany) at 80 ${ }^{\circ} \mathrm{C}$. Iron levels were determined by inductively coupled plasma optical emission spectroscopy (ICP-OES), using a SPECTRO BLUE ICP-OES instrument (Spectro, Germany) with a detection limit of $1 \mu \mathrm{g}$ Fe/L.

\section{Histological prussian blue staining}

Tissues collected were embedded and frozen in Optimal Cutting Temperature (OCT) compound (VWR) blocks. Tissue sections of 10 $\mu \mathrm{m}$ were prepared using cryostat (Leica, CM 3050) at $-20^{\circ} \mathrm{C}$. Sections were fixed in $4 \%$ paraformaldehyde for 10 minutes at room temperature and washed twice in distilled water. Prussian blue staining was then carried out using a freshly prepared solution of potassium ferrocyanide $10 \% / \mathrm{HCl} 20 \%(\mathrm{v} / \mathrm{v})$ for 30 minutes. Sections were then washed 3 times in distilled water and counterstained with $1 \%$ neutral red (5 minutes). Sections were washed twice in distilled water, dehydrated in three alcohol baths (95\%, 100\%, and 100\% ethanol; one minute each), cleared in xylene, and mounted in Eukitt ${ }^{\mathbb{R}}$ quick-hardening mounting medium (Sigma-Aldrich, Saint-Quentin Fallavier, France). Images were acquired by using a CoolSNAP color CCD camera (Photometrics, Tucson, US) coupled to a Leitz Aristoplan microscope (25 x objective, NA 0.6).

\section{Statistical analysis}

Statistical analyses were conducted using GraphPad Prism 5.0 software. Statistical significance was determined using the unpaired $t$ test. Values of $P<0.05$ were considered significant.

\section{Results}

\section{Immobilization of N6L pseudopeptide onto MNP}

N6L with a chemical structure is described in the Figure 1A, was covalently linked to MNP by a disulfide bound, yielding MNP-N6L, as illustrated in Figure 1B. Details of the protocol, characterization, and stability of such covalent nanoformulations have recently been published [24]. This work was important to determine the maximum in the amount of N6L linked to MNP that preserves the colloidal stability. For this purpose, various quantities of N6L pseudopeptide were covalently immobilized onto MNP and the zeta potential values at the different functionalization steps were monitored. This experiment has been carried out to determine the maximal concentration of N6L that could be linked to MNP (Figure S1). An increase in the zeta potential was observed due to the introduction of the cysteamine linker (preactivated MNP) and the resulting removal of carboxylic acid functions. During the N6L functionalization process, a clear increase in zeta potential was observed with the increasing amounts of covalently linked N6L until the charge switched from negative to positive. The samples functionalized with 8 and $9 \mu \mathrm{mol} \mathrm{N6L/g} \mathrm{Fe} \mathrm{were} \mathrm{unstable} \mathrm{over} \mathrm{long}$ periods of time because the peptide neutralized all negative charges on the DMSA coating. For this reason, MNP selected for in vitro and in vivo studies were covalently grafted within a range from 4.7 to $6 \mu \mathrm{mol}$ $\mathrm{N} 6 \mathrm{~L} / \mathrm{g} \mathrm{Fe}$, corresponding to 23.5 to $30 \mu \mathrm{M} \mathrm{N} 6 \mathrm{~L}$ at $5 \mathrm{mg} \mathrm{Fe} / \mathrm{mL}$ and to 20 to $26 \mathrm{~N} 6 \mathrm{~L}$ molecules per nanoparticle. The zeta potential and hydrodynamic sizes of final MNP formulations were measured at each step of the covalent functionalization (Table 1). The stability of MNP and MNP-N6L loaded at $5 \mu \mathrm{mol} \mathrm{N6L/g} \mathrm{Fe} \mathrm{of} \mathrm{NUCANT} \mathrm{was} \mathrm{studied} \mathrm{in}$ ultrapure water (Figure S2) and in complete DMEM (Figure 1C) over 2-days period by measuring the change on the hydrodynamic size. In ultrapure water MNP and MNP-N6L at 0.1 and $5 \mathrm{mg} \mathrm{Fe} / \mathrm{mL}$ remained stable and well dispersed for the 2 temperatures tested $\left(4^{\circ} \mathrm{C}\right.$ and $\left.37^{\circ} \mathrm{C}\right)$ (Figure S2). When the MNP samples were dispersed in the complete

\begin{tabular}{|c|c|c|}
\hline Sample & Zeta potential $(\mathbf{m V})$ & $\begin{array}{c}\text { Hydrodynamic diameter } \\
(\mathbf{n m})\end{array}$ \\
\hline MNP & $-44.3 \pm 0.7$ & $91.2 \pm 7.5$ \\
\hline Pre-activated MNP & $-36.6 \pm 0.8$ & $135.5 \pm 8.2$ \\
\hline $\begin{array}{c}\text { Covalent MNP-N6L }(6 \mu \mathrm{mol} \\
\text { N6L/g Fe) }\end{array}$ & $-30.2 \pm 1.2$ & $193.3 \pm 19.1$ \\
\hline
\end{tabular}

Table 1: Zeta potentials and hydrodynamic sizes of MNP at $\mathrm{pH}$ 7.5. Each value presented is the average of 3 measurements. The error on zeta potentials is the standard deviation on the 3 measurements and the error on hydrodynamic sizes is the average polydispersity index (PDI) over the 3 measurements.

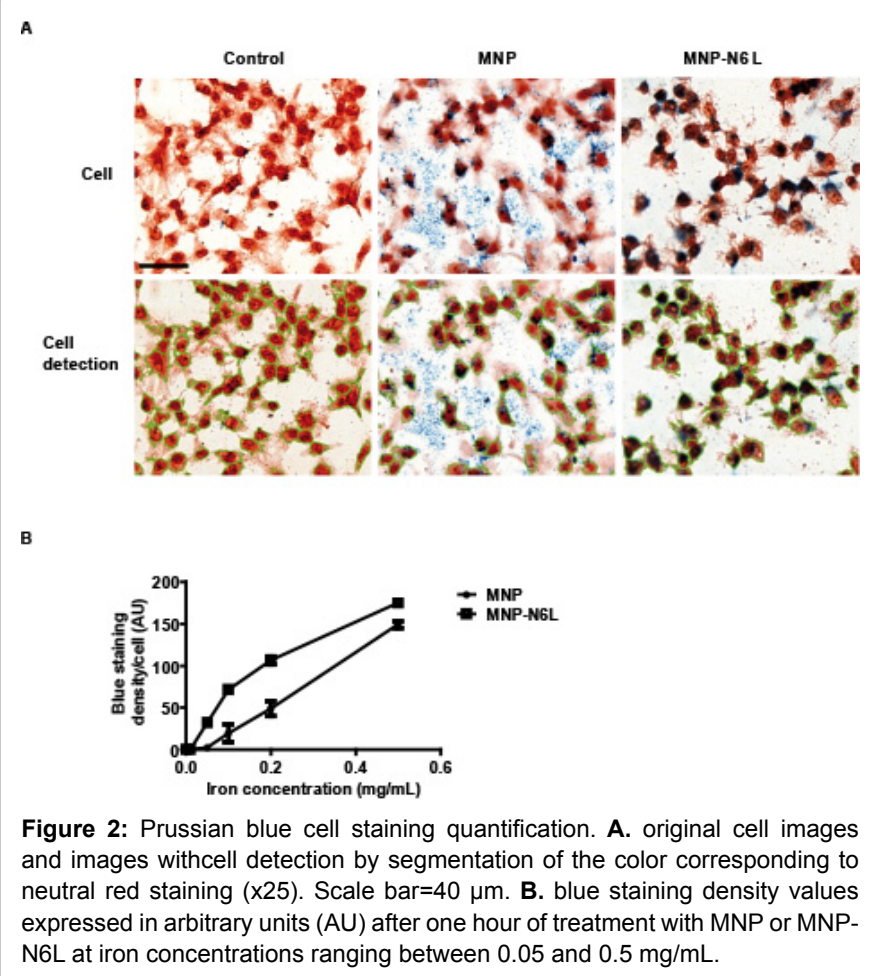

DMEM cell culture medium at $37^{\circ} \mathrm{C}$, a significant size increase was immediately observed for both formulations (MNP and MNP-N6L). This increase is not a surprise and is probably due to serum protein adsorption onto the MNP combined with a potential neutralization of charges (responsible for MNP colloidal stability). After this first size increase, the size of the particles remains unchanged for at least 48 hours and no precipitation was observed (Figure 1B).

\section{Increase in cell targeting by the presence of N6L on MNP}

A previous study showed that N6L targets tumors in mice bearing MDA-MB 231 ectopic xenografts [25]. First, to investigate the effect of the functionalization of MNP with N6L on cell targeting in vitro, cells were treated with MNP or MNP-N6L and then revealed by the presence of iron using Prussian blue staining.

In order to obtain quantitative data of the Prussian blue staining, an homemade plugin using the ImageJ software has been developed. Taking into consideration the values represented in Figure 2, all Prussian blue cell staining experiments were carried out by incubating cells with MNP or MNP-N6L at iron concentration ranging between 0.1 and $0.2 \mathrm{mg} / \mathrm{mL}$ for one hour at $37^{\circ} \mathrm{C}$. At these iron concentrations, blue density values are high enough to be quantified and far enough from saturated values. Cell kinetic targeting was further assessed by 
Citation: Sader M, Couleaud P, Carpentier G, Gilles ME, Bousserrhine N, et al. (2015) Functionalization of Iron Oxide Magnetic Nanoparticles with the Multivalent Pseudopeptide N6I for Breast Tumor Targeting. J Nanomed Nanotechnol 6: 299. doi:10.4172/2157-7439.1000299

treating the cells with MNP-N6L at $0.1 \mathrm{mg} \mathrm{Fe} / \mathrm{mL}$ for 1,3 , and 24 hours at $37^{\circ} \mathrm{C}$. As illustrated in Figure $3 \mathrm{~A}$ and $3 \mathrm{~B}$, the quantity of MNP and MNP-N6L localized at the cellular level increased in a time-dependent manner. At each time, the quantity of MNP-N6L in the cells was significantly greater compared to the non-functionalized nanoparticles (5-fold at 1 hour, 2.5 -fold at 3 hours, and 1.3 -fold at 24 hours). The differences were higher at shorter exposition times compared to 24 hours, suggesting that cell recognition is more rapid in the presence of N6L.

MNP-N6L cell targeting after 24 hours of treatment was also assessed by bright-field microscopy (Figure 3C). Both MNP and MNP-N6L bound to the cell surface were then internalized by the cells, but MNP-N6L displayed remarkably higher accumulation on cell membrane compared to MNP. Once inside the cells, MNP and MNPN6L accumulated near the nucleus.

We then investigated cell targeting at short treatment time (1 hour) by time-lapse microscopy. Incubation with MNP-N6L showed

A

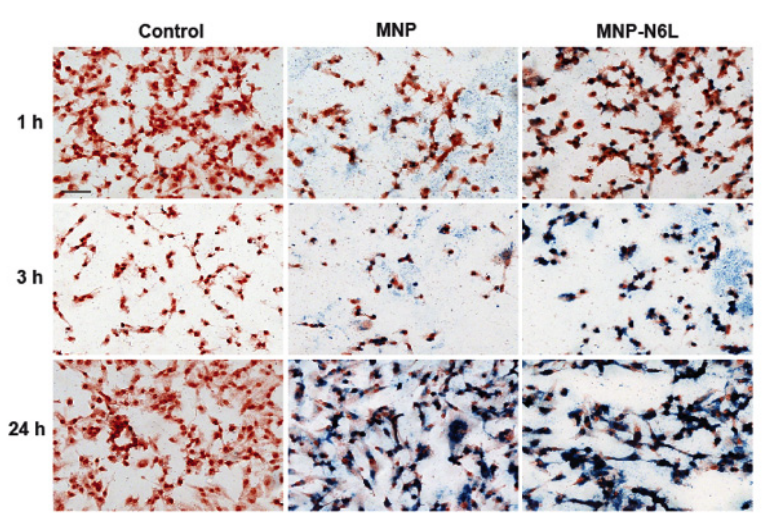

B

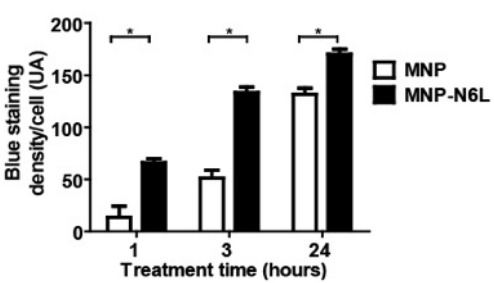

C

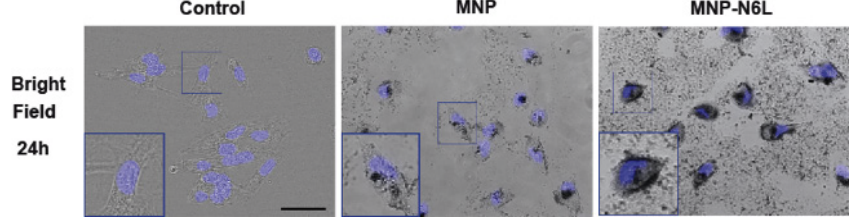

Figure 3: Time course and internalization of nanoparticles targeting MDA-MB 231 cells. A. nanoparticle detection at the cell level by Prussian blue staining Cells were treated for 1,3 , or 24 hours with MNP or MNP-N6L at $0.1 \mathrm{mg} / \mathrm{mL}$ iron and $0.47 \mu \mathrm{M}$ equivalent N6L for MNP-N6L. At each time-point, a greater mass of iron was observed with MNP-N6L. Scale bar=50 $\mu \mathrm{m}$. B. the amount of MNP bound to cell was quantified using Prussian blue staining and Image $\mathrm{J}$ software analysis. The data presents means \pm SEM of duplicate samples. Statistical significance: ${ }^{*}<0.05$ (Student $t$ test). C. cells were treated for 24 hours with MNP or MNP-N6L at $0.1 \mathrm{mg} / \mathrm{mL}$ of iron. Cells were then fixed and observed using bright-field microscopy. Nuclei were stained with DAPI and appear in blue. MNP and MNP-N6L appear near the nucleus with an important cell membrane accumulation observed with MNP-N6L. Scale bar $=40 \mu \mathrm{m}$ (Bars, SEM. ${ }^{*} \mathrm{P}<0.05$ when compared with respective controls).

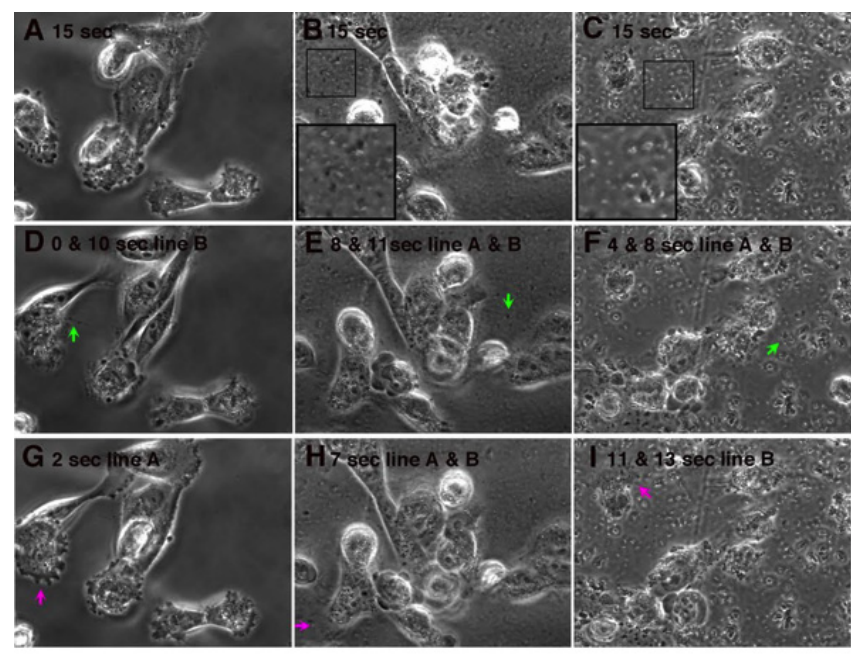

Figure 4: Time lapse of MNP and MNP-N6L targeting MDA-MB 231 cells Cells were treated with MNP and MNP-N6L $(0.15 \mathrm{mg} / \mathrm{mL}$ iron) and pictures were taken every 8 seconds for 1 hour. Selected pictures from the video are presented with the corresponding time indicated on each picture (see arrows during the video). First, second, and third columns correspond respectively to control cells, MNP, and MNP-N6L. First, second, and third line respectively show medium aspect, filopodia transit, and ruffling transit. MNP display many small particles moving throughout the entire recording corresponding to fast Brownian movement.

larger objects in the medium than incubation with MNP, suggesting nanoparticle aggregation in the culture medium. The number of MNPN6L in suspension and their Brownian movements were lower than for MNP, probably due to their faster capture by the cells, resulting in a better light transmission for MNP-N6L pictures, (Figure 4A, B, and $\mathrm{C}$, movie time $=15 \mathrm{sec}$ ).

All cells deployed filopodia among them, exhibiting some characteristics of vesicle-like transit (Figure $4 \mathrm{D}$, movie column 1 , time $=0 \mathrm{sec}$ and time $=10 \mathrm{sec}$, line B). When adding MNP, filopodia were more difficult to visualize, due to the high background of MNP in solution. Nevertheless, MNP attached to filopodia did not present observable movement in any particular direction, suggesting that MNP were not engaged in transit toward cells (Figure 4E, movie column 2 , time $=8 \mathrm{sec}$ line $\mathrm{A}$ and time $=11 \mathrm{sec}$ line $\mathrm{B}$ ). On the other hand, MNP-N6L transits through filopodia (recognizable by their rough appearance), as observed from culture medium to cell (movie column 3 , time $4 \mathrm{sec}$, line A) and from one cell to another (Figure $4 \mathrm{~F}$, Movie column 3 , time $=8 \mathrm{sec}$, Line B).

In addition, MNP-N6L transited in the ruffle-like membrane areas with strong particle capture and movement. Following the transit, MNP-N6L accumulated at the cell surface through a treadmill-like movement from the edges of the cells to the tops of the nuclei, forming a crust. (Figure 4I, Movie column 3 time $=11 \mathrm{sec}$ line $\mathrm{B}$ and time $=13$ sec line B). In control cells (Figure $4 \mathrm{G}$, movie column 1 , time $=2 \mathrm{sec}$, line A), such transit was not visible and was poorly observed in MNPtreated cells (Figure $4 \mathrm{H}$, movie column 2 , time $=7 \mathrm{sec}$, line B), and the distribution of captured particles appeared more scattered.

Altogether, these results demonstrate the potent property of N6L covalently linked to MNP to enhance tumor cell targeting, and that $\mathrm{N} 6 \mathrm{~L}$ remains active as a targeting agent after functionalization. 

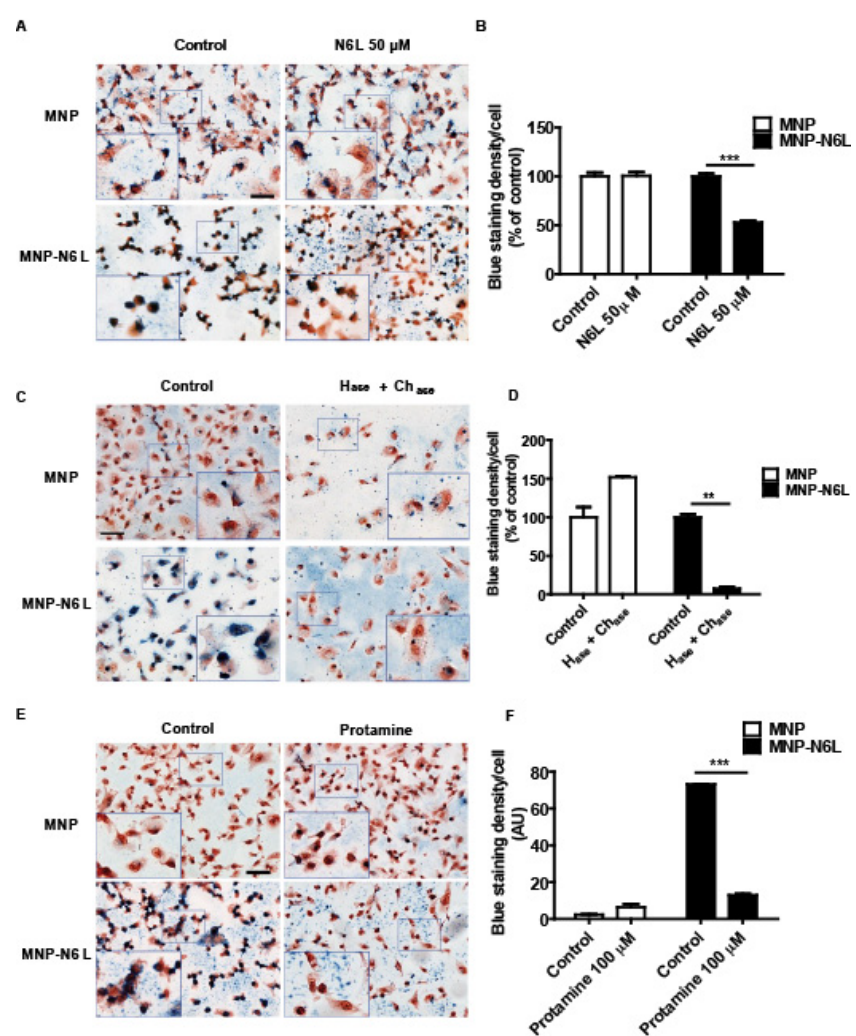

Figure 5: Implication of sulfated GAGs in MNP-N6L cell targeting. MDA-MB 231 cells were treated with either MNP or MNP-N6L at $0.15 \mathrm{mg} / \mathrm{mL}$ iron for 1 hour at $37^{\circ} \mathrm{C}$, stained with Prussian blue, and iron present in cells was quantified using Image $\mathrm{J}$ software. A and B. MNP-N6L cell targeting competed with free N6L. MDA-MB 231 cells were pretreated or not with $50 \mu \mathrm{M}$ N6L for 10 minutes before treatment with nanoparticles. A, Prussian blue images. Scale bar $=50 \mu \mathrm{m}$. B. quantification of Prussian blue staining. Bars \pm SEM $(n=4)$, ${ }^{* * *} P<0.0001$ (Student $t$ test). C and D. MDA-MB 231 cells were pretreated or not for 1 hour at $37^{\circ} \mathrm{C}$ with $0.1 \mathrm{unit} / \mathrm{mL}$ heparitinase I, II, III, and 0.1 units $/ \mathrm{mL}$ chondroitinase A,B,C, then treated with nanoparticles at $0.15 \mathrm{mg} / \mathrm{mL}$ iron for 1 hour at $37^{\circ} \mathrm{C}$. C. Prussian blue images. Scale bar $=50 \mu \mathrm{m}$. D. quantification of Prussian blue staining. Bars \pm SEM $(n=2$, representative of all experiments), ${ }^{* \star} P<0.01$ (Student $t$ test). E and F, MNP-N6L competed with protamine. MDAMB 231 cells were pretreated or not with protamine at $100 \mu \mathrm{M}$ for 10 minutes before treatment with nanoparticles. E. Prussian blue images. Scale bar $=50$ $\mu \mathrm{m}$. F. quantification of Prussian blue staining. Bars \pm SEM $(n=2),{ }^{* \star \star} P<0.0001$ (Student $t$ test).

\section{Sulfated glycosaminoglycans were mainly responsible for cell targeting by MNP-N6L}

The specificity of interaction between MNP-N6L and cells was next investigated, using N6L binding competition assay. As shown in Figure $5 \mathrm{~A}$ and $5 \mathrm{~B}$, an excess of N6L (corresponding to 100-fold more free N6L than N6L bound to MNP) significantly decreased (approximately of 50\%) MNP-N6L binding to the cells. No significant effect was observed using non-functionalized MNP, suggesting that the targeting observed is due in part to the N6L loaded onto the MNP surface.

Three molecules have been previously described as targets of N6L: nucleolin, nucleophosmin, and sulfated glycosaminoglycans (GAGs), each with an affinity constant in the nanomolar range [25-27]. We first evaluated the ability of MNP-N6L to recognize nucleolin. In a pulldown assay, either MNP or MNP-N6L were incubated with MDAMB 231 cell lysate. The unbound proteins were then washed away and nucleolin was revealed by Western blot analysis. Nucleolin was poorly detectable by non-functionalized samples, but highly detected by MNP-N6L samples (Figure S3A). These results are consistent with our previous data, showing that N6L covalently bound to MNP remains active. In order to support these results, we used siRNA for nucleolin knockdown prior to treating the cells with nanoparticles. The control carried out in each experiment showed that nucleolin was efficiently silenced (Figure S3B). Blocking nucleolin did not decrease MNP or MNP-N6L cell targeting (Figure S3C). Similar experiments carried out with nucleophosmin siRNA showed no difference between MNP and MNP-N6L cell targeting (data not shown). Together, these results provide evidence that nucleolin and nucleophosmin are not the main targets of these nanoparticles.

In latter studies, sulfated GAGs were also identified as high affinity receptor targets of the N6L [27]. In order to determine whether sulfated GAGs were involved in MNP-N6L binding to cell membrane through N6L, we carried out enzymatic degradation of chondroitin and heparan sulfates before cells were treated with the nanoparticles. Degradation of sulfated GAGs resulted in an approximately $90 \%$ decrease in MNPN6L attachment to cell membrane (Figure 5C and 5D). These results were supported by an important decrease (80\%) of MNP-N6L directed to the cells when pre-treating the cells with the protamine, a high affinity binding protein to sulfated GAGs (Figure 5E and 5F). These results suggest that sulfated GAGs are highly involved in MNP-N6L cell targeting and could also be implicated in their internalization.

\section{MNP-N6L biodistribution and in vivo tumor targeting}

Our in vitro data showed that N6L enabled MNP to target tumor cells. We then addressed the question of whether this targeting remained effective in vivo. To answer this question, MNP and MNPN6L biodistribution was assayed after intravenous administration of five repeated doses at 24 -hour intervals $(250 \mu \mathrm{g} \mathrm{Fe} /$ mouse/dose). Under these experimental conditions, treatment with MNP and MNP-N6L did not affect animal survival rate or animal behavior (rostration, pain, hyper-activity, aggressiveness and stereotype) and suggesting that these $\mathrm{MNP}$ are not toxic. Iron assay was carried out by ICP-OES in several organs, and the quantity of iron related to nanoparticles was calculated by subtracting the quantity of natural iron present in mouse organs treated with PBS. Both MNP and MNP-N6L accumulated mainly in liver $(900 \mu \mathrm{g} \mathrm{Fe} /$ tissue, approximately $70 \%$ of the total injected nanoparticles) (Figure 6B). One percent was found in spleen and less than $1 \%$ in kidney, lung and brain. Interestingly, a significantly higher amount of $\mathrm{Fe}(\mathrm{n}=5)$ was observed in the tumors treated with MNPN6L compared to MNP ( $n=4$ ) (Figure 6D). To confirm the results of total iron content, tissues were stained according to the Prussian blue protocol. Iron deriving from nanoparticles appeared as iron aggregates, whereas iron spots due to ferritin (especially in liver) appeared smaller and more scattered deposits (Figure 6A and 6C). Taken together, these data indicate that MNP-N6L is able to target the tumor as compared to the non-functionalized MNP.

\section{Discussion}

The results presented in this study demonstrate the potential of iron oxide nanoparticles covalently functionalized with the multivalent anticancer pseudopeptide N6L to target breast cancer cells in both in vitro and in vivo studies. The major challenge concerning the production of such N6L functionalized MNPs was to keep their colloidal stability. Indeed, as negative charges of the DMSA coating are responsible for the repulsion between MNP and thus their stability, the introduction of the highly positively charged N6L induces a decrease of the overall 


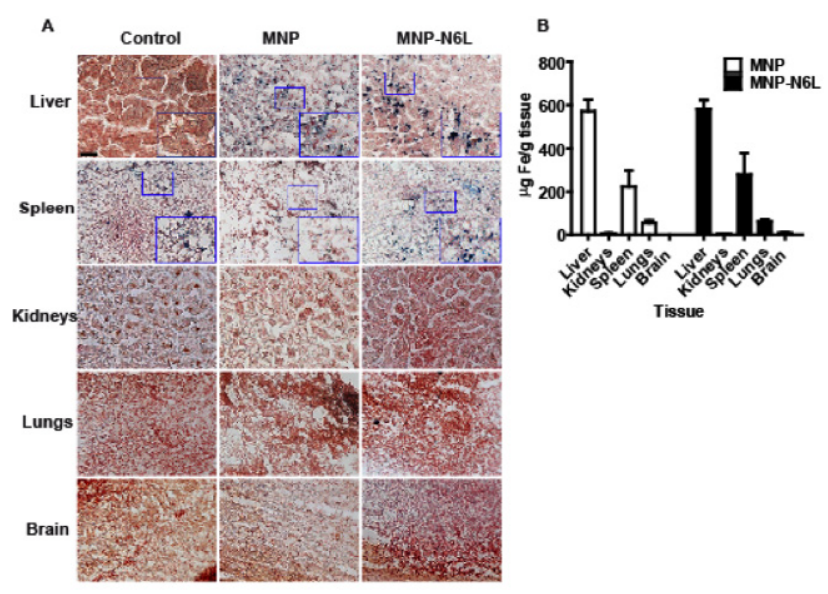

Figure 6: Tissue biodistribution and tumor targeting of MNP and MNP-N6L.

Nude mice bearing MDA-MB 231 ectopic xenografts were intravenously treated with MNP or MNP-N6L at $10 \mathrm{mg} \mathrm{Fe} / \mathrm{kg}$ of body weight (the equivalent of $0.15 \mathrm{mg} / \mathrm{kg}$ of N6L for MNP-N6L) each day for five consecutive days ( $\mathrm{n}=4$ for MNP and $n=5$ for MNP-N6L). A. MNP and MNP-N6L detection in tissues using Prussian blue staining. Scale bar represents $50 \mu \mathrm{M}$. B. quantification of iron in tissues using ICP-OES. C. Prussian blue images representing iron detection in tumor sections. Scale bar=50 $\mu$ M. D. iron quantification in tumo using ICP-OES. Iron was mainly detected in MNP-N6L treated mice. Bars \pm SEM, ${ }^{*} P<0.05$ (Student $t$ test).

charge of the MNP-N6L and therefore a lower stability. Then, it has been fundamental to control the stability of the MNP at each step of the functionalization including the pre-activation of MNP and the functionalization with N6L. The best experimental conditions for the further applications in biological medium have been accomplished by screening and selecting leading to an appropriate amount of N6L while keeping stability and biological activity. Full characterization of MNPN6L demonstrates a good stability in ultrapure water for several weeks (data not shown) and in complete DMEM for at least 2 days (Figure S2 and Figure 1B).

in vitro tumor targeting properties of MNP-N6L were first evaluated in vitro using an homemade developed Image J-based script that detects blue density staining of Prussian blue on cells and transforms it into values. This method is quantitative, easy to perform, and fast, compared to the ferrozine-based colorimetric assay, which takes about six hours, which consists of various lysis, incubation, and colorimetric steps [28]. Using MDA-MB-231 breast tumor cells, we first demonstrated that MNP-N6L displayed strong tumor targeting properties in vitro.

Since the anti-proliferative and apoptotic effects of N6L have been reported [25,27], we evaluated the effects of MNP-N6L on cell viability using the Alamar Blue method. In fact, although N6L inhibits tumor growth, the quantity of N6L linked to MNP is too low to induce an effect. Indeed, GI50 on MDA-MB 231 is about $20 \mu \mathrm{M}$ and an apoptotic effect is well observed at the GI50 concentration [25], whereas N6L bound to MNP did not exceed $1 \mu \mathrm{M}$ in the experiments conducted. Under these experimental conditions, N6L linked to the MNP induces the targeting of tumor cells but has no effect on their growth, emphasizing the use of N6L in this study, as the tumor targeting ligand of MNP (Figure S4). Furthermore, MNP functionalized or not with N6L were shown to be non-toxic at the iron concentration of $0.1 \mathrm{mg} \mathrm{Fe} / \mathrm{mL}$. This result is in agreement with our recent results showing that these types of MNP are not cytotoxic over a concentration ranging 0.01 to $0.2 \mathrm{mg} \mathrm{Fe} / \mathrm{ml}$ [29]. In this study, N6L has been attached to the MNP by electrostatic absorption. The main focus of this publication was to demonstrate the efficacy of hyperthermia treatment after intratumoral injection of the MNP-N6L.

One of the major results of the present report is that it shows that MNP-N6L mainly targets sulfated GAGs associated with the cell surface. The enzymatic degradation of sulfated GAGs was associated with almost complete inhibition of MNP-N6L cell membrane targeting (Figure 5C and 5D), suggesting that there is a strong interaction between MNP-N6L and sulfated GAGs, which could result from intermolecular ionic interactions between negatively charged sulfated GAGs and positively charged N6L. This possibility is supported by the data we have obtained which show that N6L binds to sulfated GAGs with high affinity [29]. These molecules are highly polyanionic components that play major roles in many cancer-related processes. They are implicated in cell proliferation and growth, invasion, metastasis, and angiogenesis [30]. Although our data indicate that there is no difference between N6L functionalized and non-functionalized MNP biodistribution in normal tissues, MNP-N6L were detected in the tumor at a significantly higher amount than MNP, revealing the efficient targeting activity of N6L. According to our previous data [25,27], we can assume that this targeting occurs in part through interaction between N6L and cellsurface nucleolin, which is overexpressed by tumor cells. However, several studies have shown that sulfated GAGs are overexpressed by tumor cells [31,32]. Analysis of the quantification of GAG have been evaluated from extract of tissue using carbazole assay and CS disacharide content. Using these methods, the results indicated that cancer tissue content 3 times more chondroitin sulfate than normal tissue. In addition, structural analysis of the disaccharides indicated 60 sulfate are 3 times higher in tumor tissue compared with normal tissue [33]. From these data, we can assume, with the support of our previous [27] as well as the present data in vitro, that cell-surface sulfated GAGs are implicated in this binding. Questions concerning the type of GAGs involved in this process remain open and are the subject of further studies currently underway. In this context, we have shown that chondroitin sulfate $\mathrm{A}, \mathrm{B}$, and $\mathrm{C}$ bind to N6L with high affinity compared to other GAGs, such as heparan sulfate or hyaluronic acid (manuscript submitted).

Although the affinity experiment showed that nucleolin was recognized by MNP-N6L, blocking nucleolin with siRNA (Figure S3B and S3C) or with anti-nucleolin antibody (data not shown) did not affect the binding of MNP-N6L to the cell membrane. Similar results have been obtained with other N6L targets, such as nucleophosmin (not shown). These observations suggest and support the assumption that MNP-N6L bind to other molecular cell-surface components, such as GAGs. In addition, by analogy with other studies concerning the distribution of high- and low-affinity binding sites for GAGs binding molecules, such as FGF $[34,35]$, we could hypothesize that the quantity of GAGs present at the cell surface exceeds the quantity of cellsurface nucleolin. This data is in agreement with the result obtained by inhibition of nucleolin gene expression, in which no effect on the binding of MNP-N6L to the cell surface and their internalization has been observed. In addition, it is tempting to speculate that GAGs could be involved in the process of MNP-N6L internalization. In support of this assumption, it has been shown that iron oxide magnetic nanoparticles functionalized with the arginine-rich transmembrane peptide R8 were internalized into human cervical carcinoma HeLa cells through binding to GAGs [36]. Another study have indicated that very small supermagnetic iron oxide particles have a high affinity 
Citation: Sader M, Couleaud P, Carpentier G, Gilles ME, Bousserrhine N, et al. (2015) Functionalization of Iron Oxide Magnetic Nanoparticles with the Multivalent Pseudopeptide N6I for Breast Tumor Targeting. J Nanomed Nanotechnol 6: 299. doi:10.4172/2157-7439.1000299

for GAGs and that these glycosylated molecules act as mediators for rapid intracellular uptake in THP-1 monocytic cells [37]. In a similar manner, Vats et al., showed that human umbilical endothelial cells (HUVEC) stimulated by inflammatory cytokines such as TNF $\alpha$ bind to iron oxide particles via GAGs [38]. Studies of the mechanisms by which iron oxide nanoparticles are internalized within cells via GAGs interaction remain to be undertaken. The study of such mechanisms is currently in progress in our laboratory.

In agreement to in vitro data related to the binding of MNP-N6L to tumor cells, the result of in vivo experiments indicated that MNPN6L is significantly able to target tumor. This result has been obtained using mice bearing subcutaneous tumor xenograft which are often lesser vascularized tumors compared to orthotopic xenograft [38]. This intrinsic characteristic prompted us to analyze carefully our results in relationship with the vascularization of each tumor. The result of this analysis led us to consider in the assay, only tumors having similar vascularization. In addition, this result is in agreement with recent data that we obtained showing that polyplex nanoparticles of chondroitin sulfate functionalized with N6L was able to target orthotropic pancreatic tumors (manuscript in preparation). Further studies are currently in progress to test the targeting properties of MNP-N6L in orthotopic model of breast cancer, model that we are currently developing.

In conclusion, we have developed iron oxide nanoparticles functionalized by the multivalent pseudopeptide N6L that target breast tumor by binding to nucleolin and GAGs. In light of these results, it would be interesting to improve the amount of MNP-N6L that reaches the tumor by interaction with cell-surface GAGs and nucleolin, thereby constituting a potentially promising targeting system of theranostic applications for imaging and magnetic hyperthermia, and to multifunctionalize the MNP with N6L as the targeting agent in conjunction with anticancer drugs for targeted drug delivery.

\section{Acknowledgement}

This research was funded by the CNRS and the Ministère de l'Enseignement Supérieur et de la Recherche and was carried out within the "Multifunctional Nanotechnology for Selective Detection and Treatment of Cancer" (Multifun) project funded by the European Seventh Framework Programme (FP7/2007-2013) under grant agreement number 262943.

\section{References}

1. Globocan (2012) Cancer Incidence and Mortality Worldwide: IARC Cancer Base No. 11.

2. Lammers T, Aime S, Hennink WE, Storm G, Kiessling F (2011) Theranostic nanomedicine. AccChem Res 44: 1029-1038.

3. Marciello M, Connord V, Veintemillas-Verdaguer S, Verges MJM, Carrey J, et al. (2013) Large scale production of biocompatible magnetite nanocrystals with high saturation magnetization values through green aqueous synthesis. $J$ Mater Chem B 1: 5995-6004.

4. Salas G, Casado C, Teran FJ, Miranda R, Serna CJ, et al. (2012) Controlled synthesis of uniform magnetic nanocrystals with high-quality properties for biomedical applications. J Mater Chem 22: 21065.

5. Kumar CS, Mohammad F (2011) Magnetic nanomaterials for hyperthermiabased therapy and controlled drug delivery. Adv Drug Deliv Rev 63: 789-808.

6. Cortajarena AL, Ortega D, Ocampo SM, Gonzalez-Garcia A, Couleaud P, et al. (2014) Engineering Iron Oxide Nanoparticles for Clinical Settings. Nanobiomedicine: 5772-58841.

7. Ahmed M, Douek M (2013) The role of magnetic nanoparticles in the localization and treatment of breast cancer. Biomed Res Int 2013: 281230.

8. Chen H, Wang L, Yu Q, Qian W, Tiwari D, et al. (2013) Anti-HER2 antibody and ScFvEGFR-conjugated antifouling magnetic iron oxide nanoparticles for targeting and magnetic resonance imaging of breast cancer. Int J Nanomedicine 8: 3781-3794.
9. Chao X, Zhang Z, Guo L, Zhu J, Peng M, et al. (2012) A novel magnetic nanoparticle drug carrier for enhanced cancer chemotherapy. PLoS One 7 e40388.

10. Sadeghi-Aliabadi H, Mozaffari M, Behdadfar B, Raesizadeh M, ZarkeshEsfahani H (2013) Preparation and Cytotoxic Evaluation of Magnetite (Fe3O4) Nanoparticles on Breast Cancer Cells and its Combinatory Effects with Doxorubicin used in Hyperthermia. Avicenna J Med Biotechnol 5: 96-103.

11. Koutsioumpa M, Papadimitriou E (2014) Cell surface nucleolin as a target for anti-cancer therapies. Recent Pat Anticancer Drug Discov 9: 137-152.

12. Christian S, Pilch J, Akerman ME, Porkka K, Laakkonen P, et al. (2003) Nucleolin expressed at the cell surface is a marker of endothelial cells in angiogenic blood vessels. J Cell Biol 163: 871-878.

13. Destouches D, El Khoury D, Hamma-Kourbali Y, Krust B, Albanese P, et al. (2008) Suppression of tumor growth and angiogenesis by a specific antagonist of the cell-surface expressed nucleolin. PLoS One 3: e2518.

14. Srivastava M, Pollard HB (1999) Molecular dissection of nucleolin's role in growth and cell proliferation: new insights. FASEB J 13: 1911-1922.

15. Tate A, Isotani S, Bradley MJ, Sikes RA, Davis R, et al. (2006) Met-Independent Hepatocyte Growth Factor-mediated regulation of cell adhesion in human prostate cancer cells. BMC Cancer 6: 197.

16. Said EA, Courty J, Svab J, Delbé J, Krust B, et al. (2005) Pleiotrophin inhibits HIV infection by binding the cell surface-expressed nucleolin. FEBS $\mathrm{J} 272$ 4646-4659.

17. Said EA, Krust B, Nisole S, Svab J, Briand JP, et al. (2002) The anti-HIV cytokine midkine binds the cell surface-expressed nucleolin as a low affinity receptor. J Biol Chem 277: 37492-37502.

18. Reyes-Reyes EM, Akiyama SK (2008) Cell-surface nucleolin is a signal transducing P-selectin binding protein for human colon carcinoma cells. Exp Cell Res 314: 2212-2223.

19. Shi H, Huang Y, Zhou H, Song X, Yuan S, et al. (2007) Nucleolin is a receptor that mediates antiangiogenic and antitumor activity of endostatin. Blood 110 2899-2906.

20. Bates PJ, Laber DA, Miller DM, Thomas SD, Trent JO (2009) Discovery and development of the G-rich oligonucleotide AS1411 as a novel treatment for cancer. Exp Mol Pathol 86: 151-164.

21. Hu Q, Gu G, Liu Z, Jiang M, Kang T, et al. (2013) F3 peptide-functionalized PEG-PLA nanoparticles co-administrated with thyp-1 peptide for anti-glioma drug delivery. Biomaterials 34: 1135-1145.

22. Krust B, El Khoury D, Nondier I, Soundaramourty C, Hovanessian AG (2011) Targeting surface nucleolin with multivalent HB-19 and related Nucantpseudopeptides results in distinct inhibitory mechanisms depending on the malignant tumor cell type. BMC Cancer 11: 333.

23. Birmpas C, Briand JP, Courty J, Katsoris P (2012) Nucleolin mediates the ant angiogenesis effect of the pseudopeptide N6L. BMC Cell Biol 13: 32.

24. Latorre A, Couleaud P, Aires A, Cortajarena AL, Somoza Á (2014) Multifunctionalization of magnetic nanoparticles for controlled drug release: a general approach. Eur J Med Chem 82: 355-362.

25. Destouches D, Page N, Hamma-Kourbali Y, Machi V, Chaloin O, et al. (2011) A simple approach to cancer therapy afforded by multivalent pseudopeptides that target cell-surface nucleoproteins. Cancer Res 71: 3296-3305.

26. Kossatz S, Ludwig R, Dähring H, Ettelt V, Rimkus G, et al. (2014) High therapeutic efficiency of magnetic hyperthermia in xenograft models achieved with moderate temperature dosages in the tumor area. Pharm Res 31: 32743288

27. Destouches D, Huet E, Sader M, Frechault S, Carpentier G, et al. (2012) Multivalent pseudopeptides targeting cell surface nucleoproteins inhibit cance cell invasion through tissue inhibitor of metalloproteinases 3 (TIMP-3) release. J Biol Chem 287: 43685-43693.

28. Riemer J, Hoepken HH, Czerwinska H, Robinson SR, Dringen R (2004) Colorimetric ferrozine-based assay for the quantitation of iron in cultured cells. Anal Biochem 331: 370-375.

29. Kossatz S, Grandke J, Couleaud P, Latorre A (2015) Efficient treatment of breast cancer xenografts with multifunctionalized iron oxide nanoparticles combining magnetic hyperthermia and anti-cancer drug delivery. Breast Cancer Res 17: 66. 
Citation: Sader M, Couleaud P, Carpentier G, Gilles ME, Bousserrhine N, et al. (2015) Functionalization of Iron Oxide Magnetic Nanoparticles with the Multivalent Pseudopeptide N6I for Breast Tumor Targeting. J Nanomed Nanotechnol 6: 299. doi:10.4172/2157-7439.1000299

Page 8 of 8

30. Afratis N, Gialeli C, Nikitovic D, Tsegenidis T, Karousou E, et al. (2012) Glycosaminoglycans: key players in cancer cell biology and treatment. FEBS J 279: 1177-1197.

31. Skandalis SS, Labropoulou VT, Ravazoula P, Likaki-Karatza E, Dobra K, et al. (2011) Versican but not decorin accumulation is related to malignancy in mammographically detected high density and malignant-appearing microcalcifications in non-palpable breast carcinomas. BMC Cancer 11: 314

32. Theocharis AD, Tsolakis I, Tzanakakis GN, Karamanos NK (2006) Chondroitin sulfate as a key molecule in the development of atherosclerosis and cancer progression. Adv Pharmacol 53: 281-295.

33. Weyers A, Yang B, Yoon DS, Park JH, Zhang F, et al. (2012) A structural analysis of glycosaminoglycans from lethal and nonlethal breast cancer tissues: toward a novel class of theragnostics for personalized medicine in oncology. OMICS 16: 79-89.

34. Hondermarck H, Courty J, Dauchel MC, Barritault D, Boilly B (1992) High and low affinity membrane binding sites for fibroblast growth factors in the developing chick brain. NeurosciLett 134: 247-252

35. Moscatelli D (1987) High and low affinity binding sites for basic fibroblast growth factor on cultured cells: absence of a role for low affinity binding in the stimulation of plasminogen activator production by bovine capillary endothelial cells. Journal of cellular physiology 131: 123-130.

36. Sun L, Wang J, Wang Z (2010) Recognition and transmembrane delivery of bioconjugated $\mathrm{Fe}_{2} \mathrm{O}_{3} @$ Au nanoparticles with living cells. Nanoscale 2: 269-276.

37. Ludwig A, Poller WC, Westphal K, Minkwitz S, Lättig-Tünnemann G, et al. (2013) Rapid binding of electrostatically stabilized iron oxide nanoparticles to THP-1 monocytic cells via interaction with glycosaminoglycans. Basic Res Cardiol 108: 328.

38. Vats N, Wilhelm C, Rautou PE, Poirier-Quinot M, Péchoux C, et al. (2010) Magnetic tagging of cell-derived microparticles: New prospects for imaging and manipulation of these mediators of biological information. Nanomedicine (Lond) 5: 727-738. 